\title{
LAURENT BOUKOBZA: DISAGREEING WITH YOUR BOSS MAY NOT BE EASY IN CENTRAL EUROPE
}

\author{
Laurent Boukobza (45) was appointed the new CEO of L'Oréal Hungary, Slovakia and Czech \\ Republic in 2011, after he successfully worked in top management in the U.S., Japan, Chile and his \\ native France. L'Oréal operates globally 27 brands, including Vichy, La Roche - Posay, Redken, \\ Lancôme, Ralph Lauren, Cacharel, Yves Saint Lauren, Diesel and The Body Shop. In an exclusive \\ interview for CEBR, he talks about how important it is to have the right people in the company, \\ talk to each other instead of sending emails, and not be afraid to take risks.
}

You are a top manager with a lot of experience working in different countries and cultures. How did your international career begin?

I started to work in 1992, which is basically 20 years ago, in a US based pharmaceutical corporation Warner Lambert which later became Pfizer, and stayed there for nine years. Then I moved to L’Oréal in 2001. When I signed the contract, I had no position assigned. For three months, my job was to understand the company. We have this kind of program which is called Pépinière, where we have some people coming in, we give them the opportunity to understand the company - to live inside the company. I took three months to travel, to meet some people, to adapt to the cultural change. Coming from a US company and its cultural mentality to L'Oréal, which is a bit different, I think it was a good opportunity for me to have this period without the pressure of day-to-day business, and also the flexibility to meet people, connect with people, make a network - it was very useful.

How did your professional career path go on in L'Oreal after this fresh start?

In 2001, one year after being international development director of La Roche-Posay, it was a natural decision for me to start in this division. I moved to Belgium one year later where I have been charged for Benelux for Active Cosmetic Division (Vichy, La Rose-Posay, Innéov...), so brands that we do have in the Czech Republic as well. Then I went to Japan, to be in charge of the Active Cosmetic Division again and of Galderma, L'OréalNestlé joint venture for dermatological products, and I stayed there more than two years. Then I moved back to France, where I've been in charge of the Latin American Active Cosmetic Division as a zone director from Mexico to Chile, basically travelling 10 days of the month, so my home was Terminal 2 in Roissy Charles de Gaule (a Parisian airport). After three years, I moved to Chile with my family and was in charge of L'Oréal Chile.

That sounds very exhausting. How did you like it in Chile?

It was a very special time, but we liked it as a family, because it's a great country. If you haven't been there, you have to go. You have to visit the Atacama desert, which is in the north part, and Easter Island, which is quite unique. So as a family experience, it was very interesting - it was the first experience for the kids outside, so they obviously learnt Spanish very quickly. For me, it was the first experience as a general manager of L'Oréal for the four divisions, and it was also a special time since Chile had a large earthquake in 2010 and we had very intensive reconstruction works to do. As a human experience, it was something you won't forget. We learnt a lot of things about business continuity, how to keep leadership in difficult situations. 


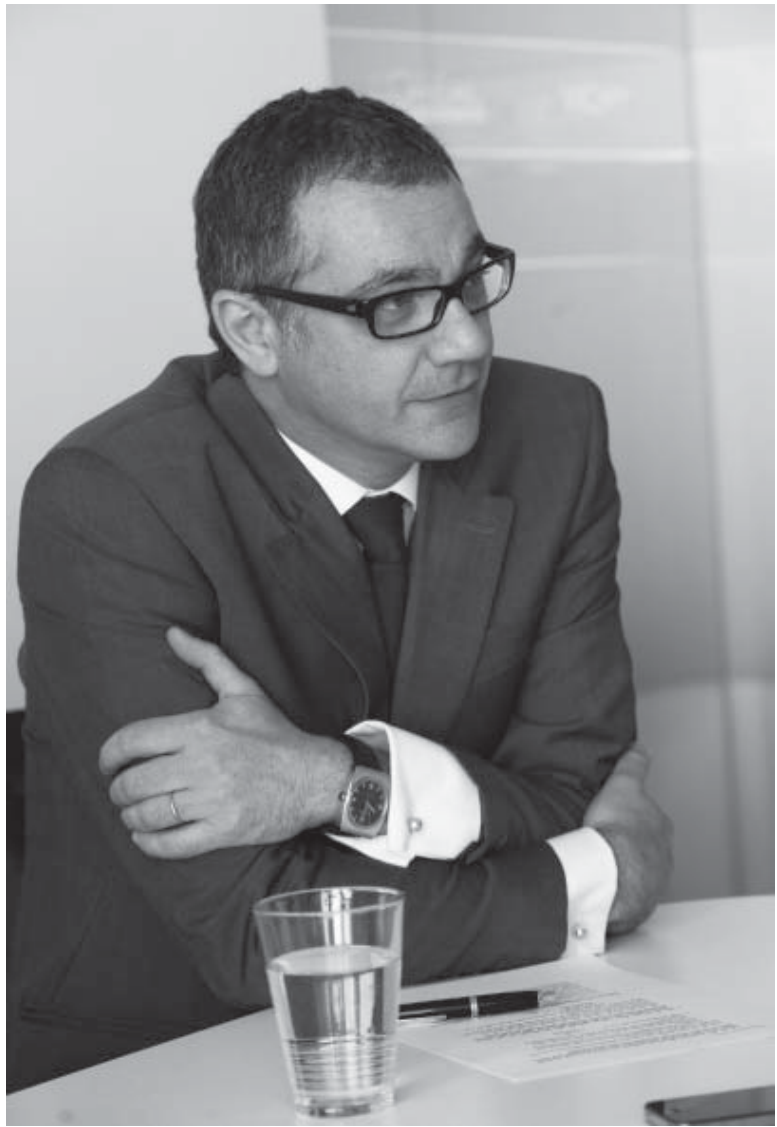

Experiencing the earthquake must have been a frightening experience for you and a difficult time for the company. Do you remember any CSR programs you did there concerning the earthquake?

We did a lot of things for our colleagues, for example securing their incomes and bonuses. We did a lot of things also for our clients, especially hairdressers, for example we helped them start again, offered them classes in order to help them face new challenges in business. We created a logo "Unidos somos más" (Together we are more), which we have used in our campaign, and last but not least, we helped a destroyed high school to create new rooms and we financed everything.

\section{Globally, L'Oréal has 27 global brands. Which of these are now present in the local markets?}

Most of them are present (21 from 27); only a few of them are missing. The objective is to roll out all the global brands in all countries, but is depends on the market's maturity. We have the objective to reach one billion consumers worldwide. I will not disclose the specific plans for the future, but to roll out all of our brands is one of the major ways to get the best fit between the potential consumers and our brands. The Czech and Hungarian markets are a little bit slow at the moment, but we have to take new initiatives to play our role of leader.

Could you tell us something about The Body Shop in the Czech Republic? There have been many questions about keeping the brand image after $L^{\prime}$ Oreal acquired the brand from its founder Anita Roddick in 2006.

The Body Shop is run totally differently from my territory of responsibility. It is the only brand which is run independently.

\section{Could you explain more precisely the interdepen- dence between the divisions and L'Oréal brands?}

We have four business divisions. The first one is the Consumer Products Division (in Czech Republic: Garnier, Maybelline New York and L'Oréal Paris), the Professional Products Division (L’Oréal Professionnel, Redken, Matrix and Kérastase), we have the Luxury Division (Lancôme, Giorgio Armani, Yves Saint Laurent, Biotherm, Helena Rubinstein, Diesel, Cacharel, Ralph Lauren and much more) and the Active Cosmetics Division (Vichy, La Roche-Posay, Innéov, Sanoflore, Roger \& Gallet). All divisions are independent with matrical reporting, specific know-how which doesn't exclude synergy, colleagues transfer, and experience sharing.

Japan, Chile and the Czech Republic are quite different in terms of culture. How about their markets and advertising?

What we know is that even if the countries are different, the market and consumer expectations of our brands are quite similar. If we look at the current cluster of Czech Republic, Hungary and Slovakia, we also have to identify the common points and the specificities. So the right balance is to find where the common points are, i.e. the common synergies that we can create - but also to enhance the specificity that we can develop, that we can identify in each country. And the right balance is not easy to find. We have to find the touch points that make the difference. There are not so many and they are not easy to find, but we keep developing specific country knowledge to be on target with our consumer.

\section{From the managerial point of view, do you see any cultural differences?}

I had to take two days of training before coming here to overcome the cultural gaps. Also having worked in Japan, in the US and in Latin America helped me to 
understand them. There are cultural differences. For me, it's very challenging and interesting to manage Czech, Slovak and Hungarian cultural aspects. Within the cluster team, we have more than 10 Hungarian people based here; we have also Slovak people in order to represent all the diversity of the cluster. Besides this synergy, we keep in each country trade marketing teams in order to keep and enhance the before mentioned specificities of the markets.

It is believed that French companies are quite closed and keep the management positions for French people.

Well, for instance, the Asia zone director is German, the Africa-Middle East director is British, and the professional products division worldwide is Belgian. There is more and more diversity in the management of L'Oréal, which is needed. We have to develop these talents locally and the main task is to develop these talents outside of their home country, which is not always easy. Managers have to know that they won't stay in the same position for 25 years; they have to accept that they can be sent to Brazil, to Japan etc.

\section{You have your own programs for recruiting students. How does it work here in the CEE Region?}

We develop connections with universities; we have campus animations, where we explain how the company works, present our brands and divisions. We have also business games in order to attract new people and identify talents, for instance L’Oréal Brandstorm. It's also an opportunity to enhance our relationships with universities, for instance to give speeches from practice, as sometimes the gap between universities and firms is large.

You are an attractive company for students; they see you as a marketing-driven company. To you perceive it the same way?

Globally, we are a research and innovation based company. We have always been so since the very beginning because our founder was a researcher. We are a beauty-focused company; we have more than 600 patents every year, always and only in beauty. When looking at our financial reports, you can see that the expenses on research and innovation are increasing every year. That is our core business. Even if beauty is not global, there is a phenomenon which we call universalization of beauty. We have labs in Brazil, China, Japan,
India and across Europe, but we have to stay in touch with the specific markets in order to understand consumer skin, hair, fashion and trends. So we are a marketing driven company in the sense that we express the results of research and innovation. The campaigns are globally based, but you can see that they slightly differ from one country to another.

Being a top manager, what do you personally believe to be the most important orientation of a global company?

I personally believe that without people and talent, we can't do anything. After that, we need to set the right direction and work all together. Eighty percent of the content of your job is imposed, but the remaining twenty percent is flexible. You have to be good at both parts. Each colleague, each group of colleagues and each division should express himself and find some creativity or new ideas, always in line with the overall direction. It is important that they are authorized to fail within these twenty percent; if not, there would not be any creativity, but only risk-adversity. But from failures we can develop further ideas. So the main idea is - go ahead, develop something new. If it works good, it's great; if it doesn't, no big deal, but instead develop something else. I can say that in Central Europe, it is difficult to take risk, to accept this management of risk. In L'Oréal, we like the confrontation of opinions. You can disagree with your boss, explain why and how. Culturally, I believe that it is not easy here in Central Europe. In Chile, it was quite similar. In Japan, it was even worse. The Japanese are totally risk-adverse. However, in these "risk-adverse" countries, you can do it by creating a little of confidence, by showing examples and making them feel that they are part of the story. If they are not in the process, they will reject it - and it's exactly the same story here.

\section{I guess that Czechs think of themselves as very} creative - they like DIY, handicrafts or fixing things. What do you personally think about that?

I think that Czechs are very creative in everything which is science-related and they have this practical creativity. I think that the Japanese could be much more creative, even if more risk-adverse, but they express creativity in domains like design or fashion.

We are in a period of various changes. What trend do you think is the most important nowadays? Is it importance of human capital or importance of technologies? 
Well, there has been a study claiming that we don't know 70 or 80 percent of the products which we will be using 20 years from now. Looking back 20 years, they had no idea what will happen today. So I don't have this kind of vision. I can say that in this region, we need to keep the human relations the center of the company. It cannot be done by sending an email. When I want to talk to people, I go to their office. Technology is a great asset, but we need to keep the human relationships inside, and not outside of the box. If you want to have a common vision, you have to meet people; we can't do that by sending fifty emails a day. Emails don't allow going in depth. We need to go into details. There are some useful new technologies like videoconferences or telecommuting; we don't want to limit these technologies, but to use them in the right direction.

To conclude, how would you briefly describe yourself?

I am trying to be as international as possible; I think I have spent more than half of my professional time outside of France. There are some common values which are always the same. To show respect to others, to be on time, is a good example of common value. I try to align them all together. You should not be playing a role; you should be yourself.
Laurent Boukobza (45) started his career outside of L'Oréal, where he worked for nearly 10 years in various companies such as Warner Lambert and Pfizer. He joined L'Oréal in 2001 in the Active Cosmetics Division as La Roche-Posay International Development Director. Following this he had several positions in the same division, first of all in Benelux then in Japan. In 2006, Laurent Boukobza became Zone Director for Active Cosmetics in Latin America and since 2009 he has been Country Managing Director for L'Oréal Chile. At the moment, he is the Country Managing Director for the Czech Republic, Hungary and Slovakia.

Authors
Tomáš Poucha
Marketing Institute
University of Economics, Prague
Faculty of Business Administration
tomas.poucha@vse.cz
Denisa Kasl Kollmannová, Ph.D.
Head of Department of Marketing
Communication and Public Relations
Charles University in Prague
Faculty of Social Sciences
Smetanovo nábřeží 6, 110 00
Prague 1, Czech Republic
kollmannova@fsv.cuni.cz

